\title{
Spray Pattern Assessment
}

National Cancer Institute

\section{Source}

National Cancer Institute. Spray Pattern Assessment. NCI Thesaurus. Code C134277.

Tests to determine the size of the mist formed by spraying. The measurement is made for the longest axis (x axis), and the ratio of longest to shortest axes ( $x / y$ ratio). 